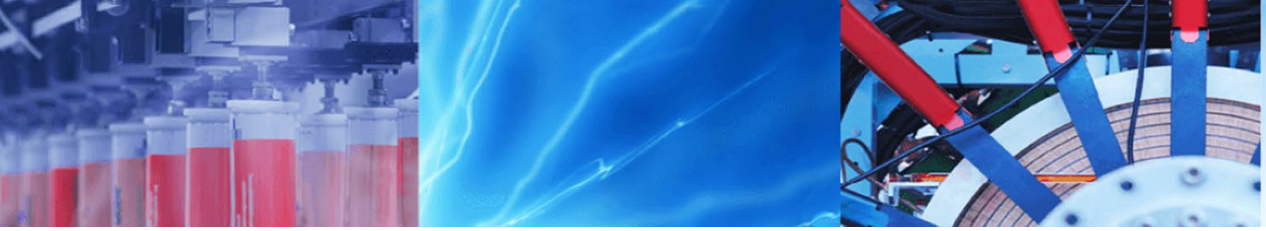

Research Article

\title{
Experiment and model of cutting force of heavy-duty milling water chamber head material
}

\author{
Yaonan Cheng ${ }^{1}$ (D) Chunyang $\mathrm{Li}^{1} \cdot$ Qihang Yuan ${ }^{1} \cdot$ Qiyao $\mathrm{Lv}^{1} \cdot \mathrm{Li} \mathrm{Liu}^{2}$
}

Received: 9 June 2019 / Accepted: 4 November 2019 / Published online: 8 November 2019

(c) Springer Nature Switzerland AG 2019

\begin{abstract}
The cyclic impact load of cutting force is one of the main factors that lead to the insert failure during the milling process. According to the asymmetrical heavy-duty milling process of water chamber head, the simulation milling experiments using actual machining parameters are conducted under laboratory conditions, and the change rule of milling force with cutting parameters is analyzed. Moreover, the simulation of interrupted cutting is carried out to study the cycle changes of cutting force and stress distribution of insert during the insert cutting-in and cutting-out workpiece. The dynamic cutting force model is established by considering the irregularity of the cutting area of circular insert and the variation of asymmetric milling thickness. Based on the analysis of comparison between the calculated value of the model and the experimental value, the cutting force model can describe the dynamic change of cutting force in milling process. It is of great significance to analyze and master the changing trend of dynamic cutting force for the study of insert failure and the formulation of reasonable processing parameters in milling process.
\end{abstract}

Keywords Heavy-duty milling · Water chamber head · Cutting force · Cutting simulation · Cutting state

\section{List of symbols}

$v_{c} \quad$ Cutting speed $(\mathrm{m} / \mathrm{min})$

$f_{z} \quad$ Feed per tooth $(\mathrm{mm} / \mathrm{z})$

$n \quad$ Spindle revolving speed $(r / m i n)$

$v_{f} \quad$ Feed speed $(\mathrm{m} / \mathrm{min})$

$a_{p} \quad$ Axial cutting depth (mm)

$a_{e} \quad$ Radial cutting depth $(\mathrm{mm})$

$\gamma_{f} \quad$ Side rake angle (degree)

$\gamma_{p} \quad$ Back rake angle (degree)

$\kappa_{r} \quad$ Cutting edge angle (degree)

$\delta \quad$ Cutting-in angle (degree)

$\theta \quad$ Cutting-out angle (degree)

$\gamma_{0} \quad$ Rake angle (degree)

$a_{0} \quad$ Relief angle (degree)

$F_{c} \quad$ Main cutting force $(\mathrm{N})$

$F_{f \prime} \quad$ Feed direction cutting force (N)

$F_{p} \quad$ Depth direction cutting force $(\mathrm{N})$ $\tau_{s} \quad$ Shear stress (MPa)

$F_{s h} \quad$ Shear force (N)

$A_{s} \quad$ Main shear area $\left(\mathrm{mm}^{2}\right)$

$A_{D} \quad$ Cutting area $\left(\mathrm{mm}^{2}\right)$

$A_{D}^{\prime} \quad$ Cutting area based on asymmetric milling $\left(\mathrm{mm}^{2}\right)$

$\beta \quad$ Friction angle (degree)

$\phi \quad$ Shear angle (degree)

$h_{D} \quad$ Cutting thickness ( $\mathrm{mm}$ )

$\theta_{0}, \theta_{1}, \theta_{2}$ Used to calculate cutting area $A_{D}$ (degree)

$\theta^{\prime} \quad$ Cutter position angle based on asymmetric milling (degree)

$\theta_{0^{\prime}}^{\prime}, \theta_{1}^{\prime}, \theta_{2}^{\prime} \quad$ Used to calculate cutting area $A_{D}^{\prime}$ based on asymmetric milling (degree)

$R \quad$ Radius of circular insert (degree)

$R_{c} \quad$ Cutter diameter $(\mathrm{mm})$

$\triangle$ Yaonan Cheng, yaonancheng@163.com | ${ }^{1}$ The Key Laboratory of National and Local United Engineering for "High-Efficiency Cutting \& Tools", Harbin University of Science and Technology, Harbin 150080, People's Republic of China. ${ }^{2}$ School of Mechanical Engineering, Tianjin University of Technology, Tianjin 300384, People's Republic of China. 


$\begin{array}{ll}h_{D}^{\prime} & \text { Cutting thickness based on asymmetric mill- } \\ & \text { ing }(\mathrm{mm}) \\ f_{z}^{\prime} & \begin{array}{l}\text { Feed per tooth based on asymmetric milling } \\ (\mathrm{mm} / \mathrm{z})\end{array}\end{array}$

\section{Introduction}

The water chamber head is critical part of nuclear evaporator, and is made of special high strength $508 \mathrm{III}$ steel. The workpiece blank is integral forging, and the size and weight are very large, which has special processing difficulty [1]. The manufacturing process is determined to be extremely manufacturing by the large size and working allowance of the part and the excellent function and special workability of material. The parts are processed mainly for heavy-duty milling, as shown in Fig. 1. During the heavy-duty milling process, the insert is subjected to huge cyclic force-thermal shock loading which causes the serious failure of the insert, as shown in Fig. 2. The cutting efficiency of water chamber head is seriously restricted and the processing cost is increased. The dynamic cutting force that the insert cutting-in and cutting-out the workpiece is one of the main factors of insert failure [2]. In the research of part cutting technology and insert technology, the cutting force model is usually established, and the insert failure is studied by combining simulation technology and cutting force data measured by cutting test $[3,4]$. Although the data of cutting experiment is reliable, a large number of experimental data are needed for the research of tool failure and the formulation of reasonable machining parameters. While the model based on the theory of cutting mechanics needs to determine many unknown parameters, the improvement of the theoretical model is convenient, and the physical behavior in cutting can be better predicted and analyzed. Therefore, the establishment of cutting force model plays an important role in the analysis of metal cutting process.

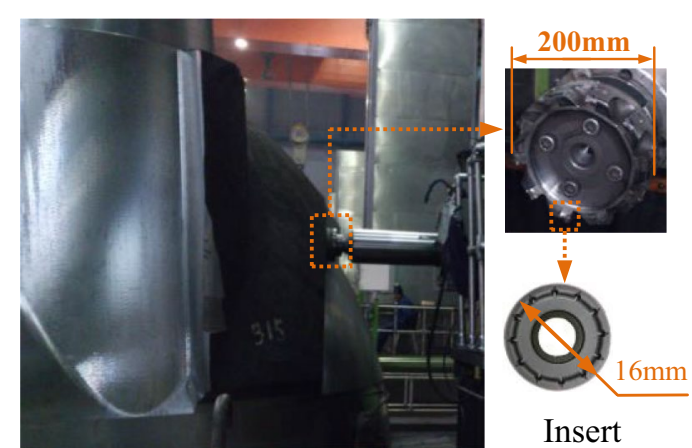

Fig. 1 Heavy-duty milling of water chamber head
At present, the main principles of the modeling of cutting force are model based on the stress-strain relationship of workpiece material and cutting mechanics; the mechanical model of irregular cutting area established by means of unit cutting force integral; the model built by artificial neural networks [5]. Adem et al. [6] proposed a linear and nonlinear mathematical force model for end milling verified by experiment. Hao et al. [7] proposed a new method for predicting milling force of surface with variable curvature. Matsumura et al. [8] established the prediction model of cutting force based on chip flow model and energy dissipation model in the milling process of complex shape section. Dong et al. [9] predicted the cutting forces during milling thin-walled part using different diameter milling cutters. Ghorbani et al. [10] established the milling force model of circular insert adopting the method of unit cutting force coefficient. Lee et al. [11] considered the friction of the cutting edge, proposed the cutting edge force of the cutting edge, and improved the mechanical model of the cutting force. Wang et al. [12] studied the three-dimensional cutting force prediction model of spiral edge milling cutter based on Merchant oblique cutting theory. Dang et al. [13] established planar milling force model considering both the bottom and side edges, and they had the conclusion that the cutting force of the bottom edge is proportional to the edge length.

Liu et al. [14-16] based on the geometric analysis of ball end milling cutter and the principle of orthogonal cutting, considering the size effect of undeformed chip thickness and the effect of effective rake angle, proposed an improved theoretical dynamic cutting force model. In the further experimental verification and application of the above model, it is found that the cutting vibration has an important influence on the dynamic cutting force. Therefore, considering the influence of the tool vibration on the machined surface, the theoretical model is improved. In order to ensure the integrity of machining dynamics, the influence of cutting parameters and the vibration of tool and workpiece on the cutting force is

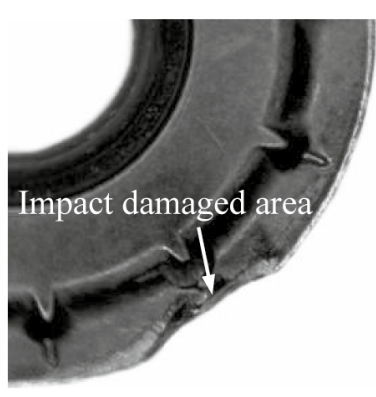

(a) Insert $A$

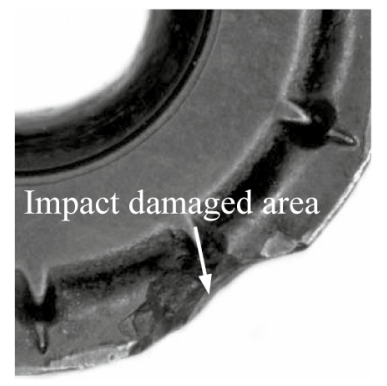

(b) Insert $B$
Fig. 2 Failure of inserts during milling process 
considered comprehensively. The dynamic simulation model is established by using Simulink software and verified by experiments. Saffar et al. [17] researched the three-dimensional cutting force and deformation of milling cutter by using the finite element simulation and experiment method, and determined that the simulation method can be used to predict the cutting force and cutter deformation. Boyd et al. [18] improved the prediction of cutting force through orthogonal cutting simulation and measured heat-mechanical load.

Generally, the established milling force models didn't indicate the change of cutting thickness in the cuttingin and cutting-out process, thus it was not possible to accurately describe the change of cutting force during interrupted cutting process. The dynamic milling force model was established based on the change of cutting thickness during asymmetric milling process of water chamber head material with method of cutting force experiments and intermittent cutting simulation. The results can provide basis for the research of insert failure.

\section{Milling experiments of water chamber head material}

\subsection{Design of milling test scheme}

Under the laboratory conditions, the simulation experiments of heavy-duty milling water chamber head material are conducted using cutting parameters in the factory so as to determine the cutting force load during milling process. The experiments adopts XW5032 vertical milling machine. The main spindle revolving speed range of machine tool is $30-1180 \mathrm{r} / \mathrm{min}$, and the feed speed range is $0-1 \mathrm{~m} / \mathrm{min}$. The workpiece material is $508 \mathrm{II}$ steel, and the size is $150 \times 100 \times 100 \mathrm{~mm}$. The cutting force is measured by the Kistler $9257 \mathrm{~B}$ piezoelectric dynamometer. The experimental equipment is shown in Fig. 3.

The experimental parameters are shown in Table 1. The diameter and number of teeth of the cutter used in practical machining are respectively $200 \mathrm{~mm}$ and 10, and used in simulation milling experiments are respectively $100 \mathrm{~mm}$ and 6 . During the milling experiments, cutting speed $v_{c}$ and feed per tooth $f_{z}$ are consistent with the actual cutting parameters. However, the feed speed of conventional milling machine in the laboratory cannot meet the requirements because of the high speed of heavy-duty milling. Thus, only two teeth are installed on the cutter for simulation experiment, which make the feed per tooth $f_{z}$ consistent with the actual processing conditions, and avoid feed

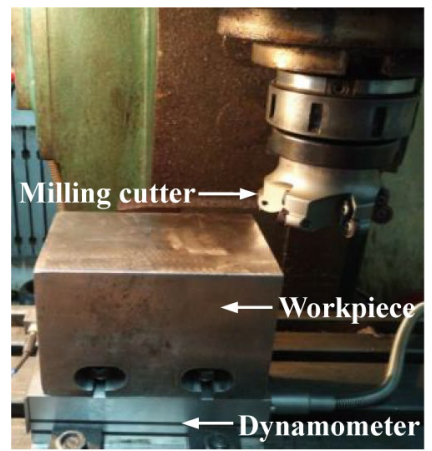

(a) Experimental equipment

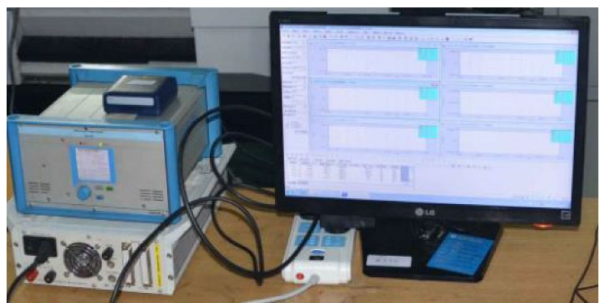

(b) Data acquisition unit

Fig. 3 Milling experimental equipment

speed exceeding the parameters of conventional milling machine.

\subsection{Analysis of experimental results}

When cutting speed $v_{c}=300 \mathrm{~m} / \mathrm{min}$ and axial cutting depth $a_{p}=2 \mathrm{~mm}$, the experimental values of the cutting force under different feeds are shown in Fig. 4.

When feed per tooth is $f_{z}=0.3 \mathrm{~mm} / \mathrm{z}$ and axial cutting depth $a_{p}=2 \mathrm{~mm}$, the experimental values of the cutting force under different cutting speeds are shown in Fig. 5. The increase of feed per tooth leads to the increase of cutting area, so the cutting force is increasing. From the experimental value, it can get that the cutting force increased by about $29 \%$ when the feed per tooth is $f_{z}=0.38 \mathrm{~mm} / \mathrm{z}$ relative to $f_{z}=0.21 \mathrm{~mm} / \mathrm{z}$. As the cutting speed increases, the cutting force decreases slightly. Through the analysis of experimental data, it can know that when the cutting speed $v_{c}=350 \mathrm{~m} /$ min, the cutting force is $10 \%$ less than that of $v_{c}=250 \mathrm{~m} / \mathrm{min}$.

\section{Research on cutting state of insert during interrupted cutting}

\subsection{Determination of cutting-in and cutting-out type of insert}

In the process of cutting in and cutting out the workpiece, the insert can be easily breakage because of the 
Table 1 Milling experimental conditions

\begin{tabular}{lll}
\hline Cutting method & Heavy-duty milling & Simulation milling \\
\hline Cutter diameter $(\mathrm{mm}) /$ number of teeth & $200 / 10$ & $100 / 2$ \\
Cutting speed $v_{c}(\mathrm{~m} / \mathrm{min}) /$ spindle revolv- & $250 / 398$ & $250 / 796$ \\
ing speed $n(\mathrm{r} / \mathrm{min})$ & $300 / 478$ & $300 / 955$ \\
& $350 / 557$ & $350 / 1115$ \\
Feed speed $v_{f}(\mathrm{~m} / \mathrm{min}) /$ feed per tooth $f_{z}$ & $1 / 0.21$ & $0.402 / 0.21$ \\
$(\mathrm{~mm} / \mathrm{z})\left(v_{c}=300 \mathrm{~m} / \mathrm{min}\right)$ & $1.4 / 0.3$ & $0.574 / 0.3$ \\
& $1.8 / 0.38$ & $0.726 / 0.38$ \\
Axial cutting depth $a_{p}(\mathrm{~mm})$ & 2 & 2 \\
Radial cutting depth $a_{e}(\mathrm{~mm})$ & 100 & 50 \\
Cutter type & WIDIA M4000D200Z10ADJ & ZCCC FMR04-100-B32-RD16-06 \\
Insert type & WIDIA RCMT1606M043M & WIDIA RDMT1605MOTX \\
\hline
\end{tabular}

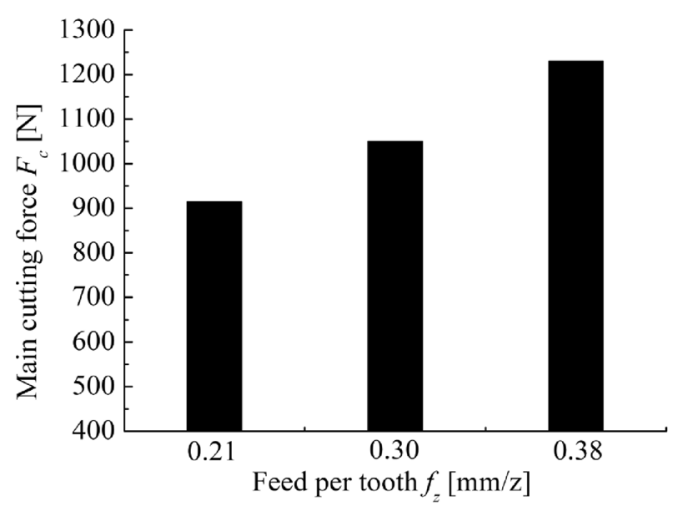

Cutting speed $v_{c}=300 \mathrm{~m} / \mathrm{min}$; Axial cutting depth $a_{p}=2 \mathrm{~mm}$

Fig. 4 Influence of feed per tooth on main cutting force. Cutting speed $v_{c}=300 \mathrm{~m} / \mathrm{min}$; Axial cutting depth $a_{p}=2 \mathrm{~mm}$

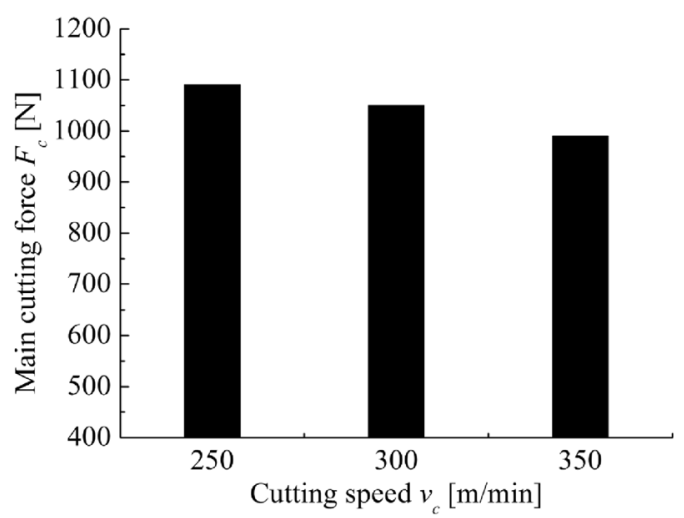

Feed per tooth $f_{z}=0.3 \mathrm{~mm} / \mathrm{z}$; Axial cutting depth $a_{p}=2 \mathrm{~mm}$

Fig. 5 Influence of cutting speed on main cutting force. Feed per tooth $f_{z}=0.3 \mathrm{~mm} / \mathrm{z}$; Axial cutting depth $a_{p}=2 \mathrm{~mm}$

change and impact of cutting force and heat. Firstly, it is necessary to determine the cutting-in type of insert in the heavy-duty milling water chamber head. The radial

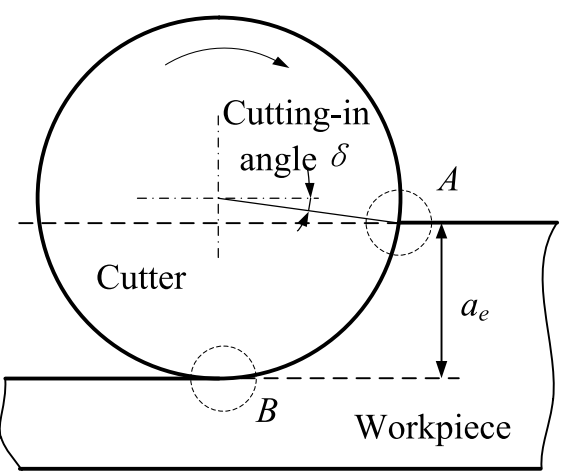

(a) Milling process

Cutting-in

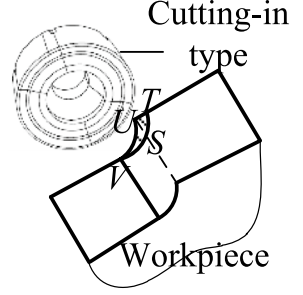

(b) Schematic diagram of $A$

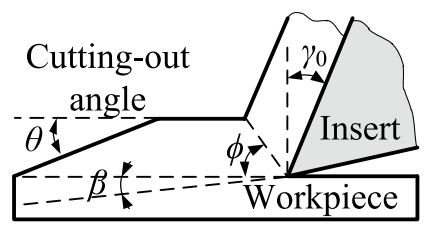

(c) Schematic diagram of $B$
Fig. 6 Angles of cutting-in and cutting-out of the insert

cutting depth of the milling cutter is about $100 \mathrm{~mm}$. The asymmetric milling method is adopted, as shown in Fig. 6a), cutting-in angle $\delta$ of cutter is close to $0^{\circ}$. By measuring the tool angle, side rake angle is $\gamma_{f}=4.88^{\circ}$, back rake angle is $\gamma_{p}=8.77^{\circ}$. Since the insert is round, the average cutting edge angle $\kappa_{r}=\arcsin \left(a_{p} / 2 R\right)^{1 / 2}=20.7^{\circ}$ was adopted. And side rake angle $\gamma_{f}>$ cutting-in angle $\delta=3^{\circ}$. The discriminant of cutting-in type is Eq. (1):

$\cot \kappa_{r}<\frac{\tan \gamma_{p}}{\tan \gamma_{f}-\tan \delta}$ 
Fig. 7 Two-dimensional simulation model of tool and workpiece

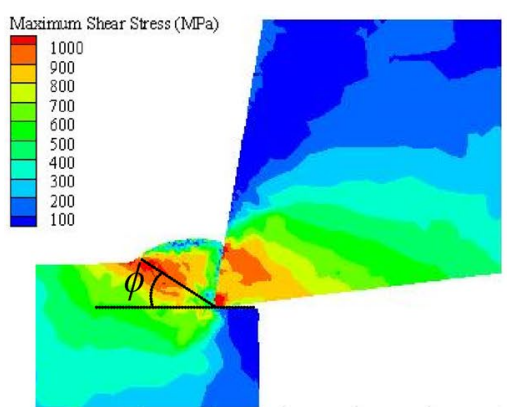

(a) Cutting-in process

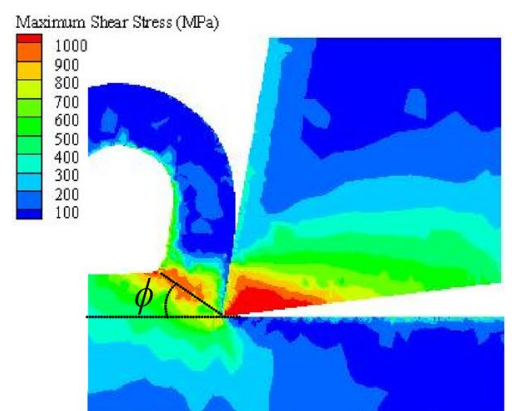

(b) Cutting process

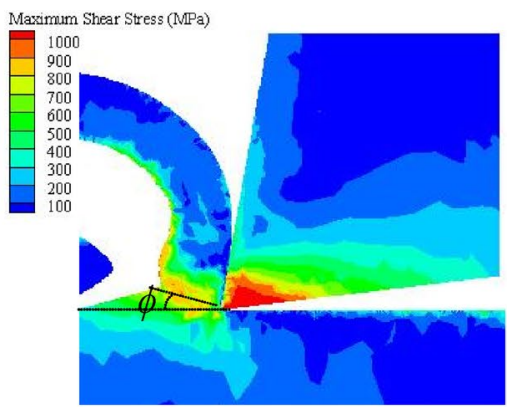

(c) Cutting-out process

Fig. 8 Stress distribution of insert during intermittent cutting process

According to the discriminant (1), it can be concluded that cutting-in type of insert is $S$ type, as shown in Fig. 6b). The cutting-in point of insert is on the cutting edge. In the cutting-out process of interrupted cutting, the shear mechanism changes greatly and the shear direction is deflected. The cutting thickness of insert in the cutting-out location is gradually reduced because of asymmetric milling which causes cutting-out angle $\theta$ is less than $90^{\circ}$, as shown in Fig. $6 \mathrm{c}$ ). Shear angle is deflected in the cutting-out process, and it can cause stress field change, cutting-out breakage and initiation and extension of cracks of insert. The shear angle deflection causes the load of rake face to be concentrated on cutting edge, which leads to instant increase of the stress of the cutting edge and the chance of the cutting edge breaking.

\subsection{Simulation of stress-temperature distribution of insert}

The two-dimensional simulation process of the interrupted cutting of water chamber head is shown in Fig. 7. The cutting parameters: $v_{c}=300 \mathrm{~m} / \mathrm{min}, f_{z}=0.3 \mathrm{~mm} / \mathrm{z}$, $a_{p}=2 \mathrm{~mm}$. Cutting-out angle is $\theta=30^{\circ}$. Rake angle of insert is $\gamma_{0}=10^{\circ}$, and relief angle is $a_{0}=7^{\circ}$. Insert basis material is P-type cemented carbide, and coating is TiAIN material.

Combining with Figs. 8 and 9, the insert is cutting in the workpiece by the $S$ type, and the stress is concentrated on the cutting edge, the cutting edge gradually contacts the workpiece. When the insert is cutting in the workpiece completely, the cutting force and the stress of cutting part

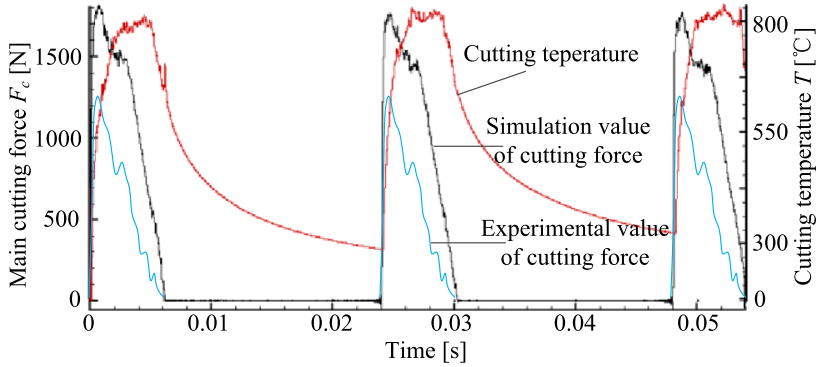

Fig. 9 Change law of cutting force and temperature during intermittent cutting process

of the insert reach the maximum. When the cutting state is stable, the cutting force decreased slightly and gradually stabilized. Cutting temperature of insert experiences gradual rise and maintains a smooth process. When the insert is cutting out the workpiece, cutting-out angle is very small. Although there is no negative shear phenomenon, the shear angle still has a deflection, and minimum shear angle is close to $0^{\circ}$. The insert-chip contact length becomes shorter, cutting force is focused on cutting edge, which is easy to cause cutting-out breakage of insert. The insert is subjected to cyclic loading during the interrupted cutting process, and the cutting force changed from 0 to about $1500 \mathrm{~N}$. 


\section{Establishment of dynamic cutting force model}

According to the dynamic response characteristics of the cutting process [19], the spindle of the machine tool drives the insert cuts into the workpiece material. Shear and extrusion are formed in the main shear zone where has shear strain. The cutting force of insert can be calculated through shear stress in the main shear zone. In order to calculate the load on the insert, based on the force relationship in the orthogonal cutting theory [20], the geometric shape and the force situation of the tool are assumed: (1) the cutting edge of the insert is assumed to be a straight edge, regardless of the friction force in the third deformation zone; (2) the normal stress $\sigma_{s}$ and shear stress $\tau_{s}$ in the shear plane are assumed to be fixed; (3) It is assumed that the force applied on the chip and tool contact area is a pair of equilibrium forces with the resultant force applied on the shear plane.

The relationship of cutting forces is shown in Fig. 10. The insert is subjected to the main cutting force $F_{C}$, feed direction cutting force $F_{f}$ and depth direction cutting force $F_{p}$.

The cutting force mainly comes from shear stress $\tau_{s}$ in main shear area. Firstly, we can calculate shear force $F_{\text {sh }}$ as follow:

$F_{s h}=\tau_{s} A_{s}=\frac{\tau_{s} A_{D}}{\sin \phi}$

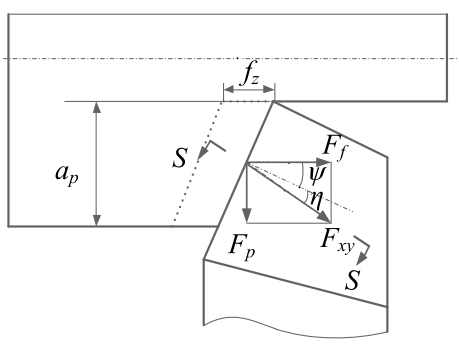

(a) Cutting force composition of inclined cutting

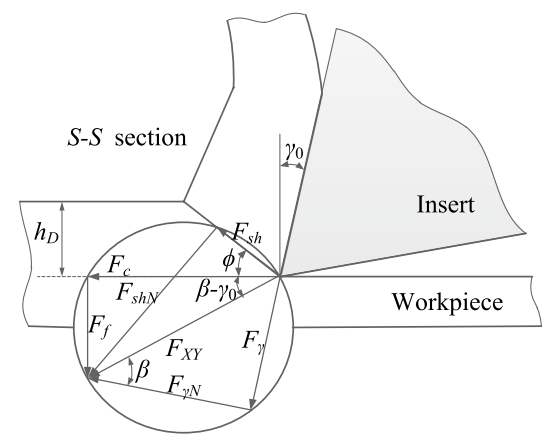

(b) Relation of cutting force and angle of $S-S$ section

Fig. 10 Composition of the cutting force where $F_{s h}$ and $\tau_{s}$ are shear force and shear stress in the main shear zone; $A_{s}$ is the area of the main shear area; $A_{D}$ is the area of the cutting area.

The main cutting force of insert is expressed as follows:

$F_{c}=\frac{\tau_{s} A_{D} \cos \left(\beta-\gamma_{0}\right)}{\sin \varphi \cos \left(\varphi+\beta-\gamma_{0}\right)}$

where $\beta$ is the friction angle; $\gamma_{0}$ is the rake angle; $\phi$ is the shear angle.

Round carbide insert is used for the heavy-duty milling process of the water chamber head. The cutting area of the insert is the irregular shape of the crescent, as shown in Fig. 11. The cutting thickness $h_{D}$ of the insert is constantly changing. An integral method is used to calculate the cutting area:

$A_{D}=\int_{\theta_{0}}^{\theta_{2}} d \theta \int_{\rho}^{R} r d r$

where $R$ is the radius of circular insert.

Angles $\theta_{0}, \theta_{1}$ and $\theta_{2}$ in Fig. 11 can be expressed respectively by:

$\left\{\begin{array}{l}\theta_{0}=\arcsin \left[\left(R-a_{p}\right) / R\right] \\ \theta_{1}=\arctan \left[\left(R-a_{p}\right) /\left(\sqrt{R^{2}-\left(R-a_{p}\right)^{2}}-f_{z}\right)\right] \\ \theta_{2}=\pi-\arccos \left(f_{z} / 2 R\right)\end{array}\right.$

In the case of $\theta_{0} \leq \theta \leq \theta_{1}, \rho=\mathrm{OB}$. In the case of $\theta_{1} \leq \theta \leq \theta_{2}$, $\rho=\mathrm{OA}$. $\rho$ can be expressed by:

$\rho= \begin{cases}\frac{R-a_{p}}{\sin \theta} & \theta<\theta_{1} \\ R-f_{z} \cos \theta & \theta \geq \theta_{1}\end{cases}$

Therefore, the cutting thickness equation is:

$h_{D}= \begin{cases}R-\frac{R-a_{p}}{\sin \theta} & \theta<\theta_{1} \\ f_{z} \cos \theta & \theta \geq \theta_{1}\end{cases}$

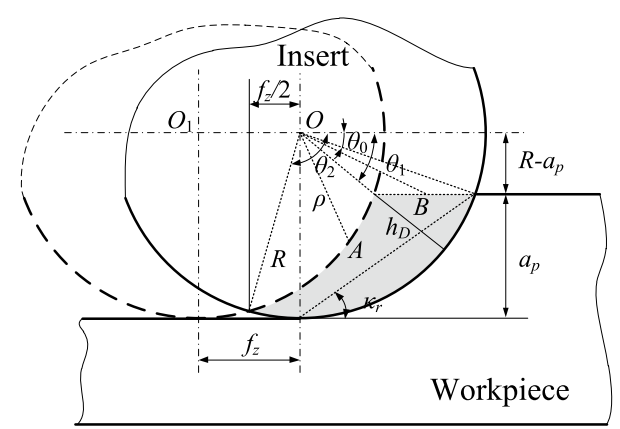

Fig. 11 Cutting area of circular insert 
The cutting area $A_{D}$ is divided into two parts by Angle $\theta_{1}$, so Eq. (4) can be expressed as:

$A_{D}=\int_{\theta_{0}}^{\theta_{1}} d \theta \int_{h / \sin \theta}^{R} r d r+\int_{\theta_{1}}^{\theta_{2}} d \theta \int_{R-f_{z} \cos \theta}^{R} r d r$

where $h$ is equal to $R$ subtract $a_{p}$.

The Eq. (8) can be calculated as:

$$
\begin{aligned}
A_{D}= & \frac{R^{2}\left(\theta_{1}-\theta_{0}\right)+h^{2} \cot \left(\theta_{1}-\theta_{0}\right)}{2}+R f_{z} \sin \left(\theta_{2}-\theta_{1}\right) \\
& -\frac{f_{z}^{2}}{8}\left[2\left(\theta_{2}-\theta_{1}\right)+\sin 2\left(\theta_{2}-\theta_{1}\right)\right]
\end{aligned}
$$

Tool cutting edge angle of circular insert is changing, and the range is $0^{\circ}-90^{\circ}$. In the calculation process, the tool cutting edge angle is adopted as follow:

$\kappa_{r}=\arcsin \sqrt{\frac{a_{p}}{2 R}}$

The $A_{D}$ in Eq. (9) is calculated based on feed per tooth $f_{z}$. Substituting the above formula into Eq. (3), the cutting force of the cutting area $A_{D}$ can be calculated. Due to the asymmetric milling process of water chamber head, the cutting area of the insert is constantly changing with the rotation of the cutter, as shown in Fig. 12a). The cutting thickness is reduced to zero in the cutting-out workpiece, and the cutting trajectory of the cutter is similar to the cutting area

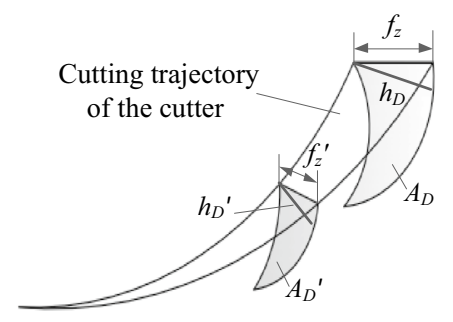

(a) Cutting area of insert in different position

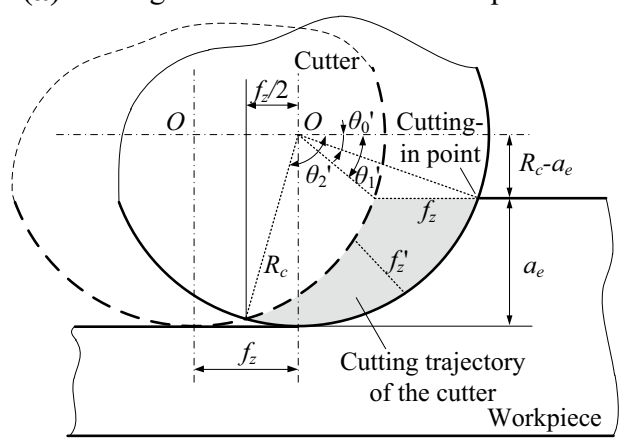

(b) Analysis of cutting figure

Fig. 12 Variation of cutting thickness of insert during milling figure of Fig. 11. When the position angle of cutter tooth is $\theta_{0^{\prime}}^{\prime}$ the insert cuts in the workpiece by type $S$, and the cutting in point is shown in Fig. 12b). The equation of $f_{Z}^{\prime}$ in cutting process is:

$f_{z}^{\prime}= \begin{cases}f_{z} \cos \theta^{\prime} & \theta^{\prime} \geq \theta_{1}^{\prime} \\ R_{c}-\frac{R_{c}-a_{e}}{\sin \theta^{\prime}} & \theta^{\prime}<\theta_{1}^{\prime}\end{cases}$

where $R_{c}$ is cutter diameter; $a_{e}$ is radial cutting depth of cutter; $\theta^{\prime}$ is position angle of cutter tooth. The Eq. (11) is substituted in Eq. (5), and the dynamic three angles are calculated respectively.

The position angle $\theta_{0}^{\prime}, \theta_{1}^{\prime}$ and $\theta_{2}^{\prime}$ of cutter tooth in Fig. 12b) can be expressed by:

$\left\{\begin{array}{l}\theta_{0}^{\prime}=\arcsin \left[\left(R_{c}-a_{e}\right) / R_{c}\right] \\ \theta_{1}^{\prime}=\arctan \left[\left(R_{c}-a_{e}\right) /\left(\sqrt{R_{c}^{2}-\left(R_{c}-a_{e}\right)^{2}}-f_{z}\right)\right] \\ \theta_{2}^{\prime}=\pi-\arccos \left(f_{z} / 2 R_{c}\right)\end{array}\right.$

Thus, in the milling process, the dynamic cutting thickness $h_{D}^{\prime}$ can be expressed as:

$h_{D}^{\prime}= \begin{cases}R-\frac{R-a_{p}}{\sin \theta} & \theta<\theta_{1} \\ f_{z}^{\prime} \cos \theta & \theta \geq \theta_{1}\end{cases}$

Replace $f_{z}$ with $f_{z}^{\prime}$ in Eqs. (5) and (9), the calculation formula of the instantaneous cutting area of the insert is obtained:

$$
\begin{aligned}
A_{D}^{\prime}= & \frac{R^{2}\left(\theta_{1}-\theta_{0}\right)+h^{2} \cot \left(\theta_{1}-\theta_{0}\right)}{2}+R f_{z}^{\prime} \sin \left(\theta_{2}-\theta_{1}\right) \\
& -\frac{f_{z}^{\prime 2}}{8}\left[2\left(\theta_{2}-\theta_{1}\right)+\sin 2\left(\theta_{2}-\theta_{1}\right)\right]
\end{aligned}
$$

Therefore, using the parameters of Table 2, the dynamic main cutting force of the circular inert in milling process is calculated according to Eqs. (3) and (14), as shown in Fig. 13. When the position angle of cutter tooth is $\theta_{1}^{\prime}$, the cutting force reaches the maximum, and then decreases gradually. When the insert is cutting out, the cutting force is zero.

Table 2 Cutting conditions and model parameters

\begin{tabular}{lccclll}
\hline Physical quantity & Value & & & Physical quantity & Value \\
\hline$f_{z}(\mathrm{~mm} / \mathrm{z})$ & 0.21 & 0.3 & 0.38 & $R(\mathrm{~mm})$ & 8 \\
$\theta_{1}(\mathrm{deg})$ & 49.7 & 50.3 & 50.7 & $\tau_{s}(\mathrm{MPa})$ & 498 \\
$\beta$ (deg) & 44.6 & 38.9 & 29.4 & $a_{p}(\mathrm{~mm})$ & 2 \\
$\phi$ (deg) & 27.7 & 30.5 & 35.3 & $\theta_{0}(\mathrm{deg})$ & 48.6 \\
\hline
\end{tabular}




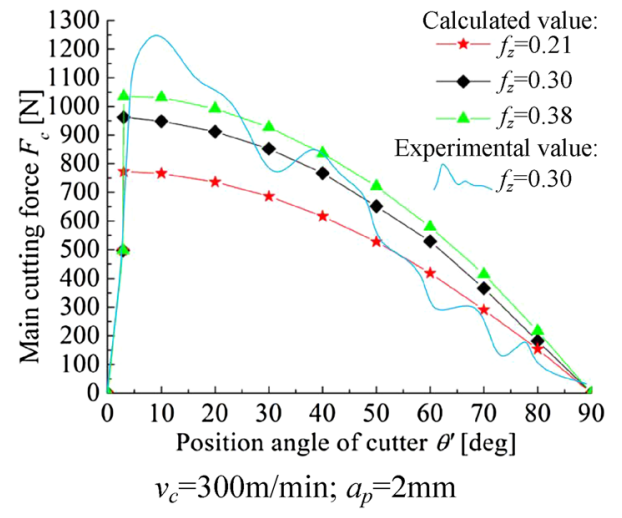

Fig. 13 Dynamic main cutting force during cutting in and cutting out workpiece. $v_{c}=300 \mathrm{~m} / \mathrm{min} ; a_{p}=2 \mathrm{~mm}$

\section{Conclusions}

Through the simulated heavy-duty milling experiments, cutting simulation and establishment of dynamic cutting force model, the mechanical load characteristics of damage and failure of carbide insert were studied. The conclusions are as follows:

1. The cutting speed was $300 \mathrm{~m} / \mathrm{min}$, feed rate of each tooth was $0.3 \mathrm{~mm}$, and axial cutting depth was $2 \mathrm{~mm}$ during heavy-duty milling of water chamber head. The maximum main cutting force reaches $1050 \mathrm{~N}$ in the milling process. The cutting force increased with the increase of feed rate of each tooth. The increase of cutting speed had little effect on the cutting force.

2. When the insert was cutting into workpiece, main cutting edge was the first contact with the workpiece, and the stress was concentrated on the cutting edge. In the process of cutting out, the shear angle was deflected and decreased, and the stresses gradually converged to the cutting edge. The above conditions were provided for insert breakage.

3. The calculation method of irregular cutting area of circular insert was presented during asymmetric milling with the goal of establishing mathematical model of dynamic cutting force of circular insert in asymmetric milling process. The dynamic cutting forces were calculated by using different position angles of cutter teeth. The model was verified by experiment value. The calculated value of the model can be used to represent the change of cutting force during milling process.
Funding This research was financially supported by National Natural Science Foundation of China (No. 51675145).

\section{Compliance with ethical standards}

Conflict of interest The authors declare that they have no competing interests.

\section{References}

1. Liu L, Cheng YN, Wang T, Han Y, Xu M (2015) Investigations of the high-temperature deformation behaviour and fatigue mechanisms of cemented carbide inserts during cutting 508III steel. Int J Manuf Res 10(4):299-312

2. He GH, Liu XL, Wen X, Wu CH, Li LX (2017) An investigation of the destabilizing behaviors of cemented carbide tools during the interrupted cutting process and its formation mechanisms. Int J Adv Manuf Technol 89(5-8):1959-1968

3. Chen Y, Li H, Wang J (2015) Analytical modelling of cutting forces in near-orthogonal cutting of titanium alloy Ti6Al4 V. Proc Inst Mech Eng Part C: J Mech Eng Sci 229(6):1122-1133

4. Zhang S, Li JF, Sun J, Jiang F (2010) Tool wear and cutting forces variation in high-speed end-milling Ti-6Al-4V alloy. Int J Adv Manuf Technol 46(1-4):69-78

5. Wan M, Zhang WH, Tan G, Qin GH (2007) New cutting force modeling approach for flat end mill. Chin J Aeronaut 20(3):282-288

6. Adem KAM, Fales R, El-Gizawy AS (2015) Identification of cutting force coefficients for the linear and nonlinear force models in end milling process using average forces and optimization technique methods. Int J Adv Manuf Technol 79(9-12):1671-1687

7. Hao HY, Wang BS, Tang WC (2015) Prediction of instantaneous milling force taking runout into account in peripheral milling of curved surface. Int J Adv Manuf Technol 79(1-4):49-56

8. Matsumura T, Usui E (2010) Predictive cutting force model in complex-shaped end milling based on minimum cutting energy. Int J Mach Tools Manuf 50(5):458-466

9. Dong X, Zhang W, Sun J (2016) The estimation of cutting force coefficients in milling of thin-walled parts using cutter with different tooth radii. Proc Inst Mech Eng B J Eng Manuf 230(1):194-199

10. Ghorbani H, Moetakef-Imani B (2016) Specific cutting force and cutting condition interaction modeling for round insert face milling operation. Int J Adv Manuf Technol 84(5-8):1705-1715

11. Lee $P$, Altintas $Y$ (1996) Prediction of ball-end milling forces from orthogonal cutting data. Int J Mach Tools Manuf 36(9):1059-1072

12. Wang YQ, Liu HB (2011) A novel mechanics model of parametric helical-end mills for 3D cutting force prediction. Proc Inst Mech Eng C J Mech Eng 225(7):1693-1702

13. Dang JW, Zhang WH, Yang Y, Wan M (2010) Cutting force modeling for flat end milling including bottom edge cutting effect. Int J Mach Tools Manuf 50(11):986-997

14. Liu XW, Cheng K, Longstaff AP, Widiyarto MH, Ford D (2005) Improved dynamic cutting force model in ball-end milling. Part I: theoretical modelling and experimental calibration. Int J Adv Manuf Technol 26(5-6):457-465

15. Liu XW, Cheng K, Webb D, Longstaff AP, Widiyarto MH (2004) Improved dynamic cutting force model in peripheral milling. Part II: experimental verification and prediction. Int J Adv Manuf Technol 24(11-12):794-805 
16. Liu X, Cheng K (2005) Modelling the machining dynamics of peripheral milling. Int J Mach Tools Manu 45(11):1301-1320

17. Saffar RJ, Razfar MR, Zarei O, Ghassemieh E (2008) Simulation of three-dimension cutting force and tool deflection in the end milling operation based on finite element method. Simul Model Pract Theroy 16(10):1677-1688

18. Boyd JM, Hosseinkhani K, Veldhuis SC, Ng E (2016) Improved prediction of cutting forces via finite element simulations using novel heavy-load, high-temperature tribometer friction data. Int J Adv Manuf Technol 86(5-8):2037-2045
19. Cheng K (ed) (2008) Machining dynamics: fundamentals, applications and practices. Springer, Berlin

20. Merchant ME (1945) Mechanics of the metal cutting process. I. Orthogonal cutting and a type 2 chip. J Appl Phys 16(5):267-275

Publisher's Note Springer Nature remains neutral with regard to jurisdictional claims in published maps and institutional affiliations. 